DOI: http://dx.doi.org/10.30684/etj.37.4C.12

The First International Conference of Engineering Education (1 ${ }^{\text {st }}$ ICEE 2019), Iraq, Baghdad, 9-10 January 2019

\begin{abstract}
Jalal M. Jalil
Electromechanical

Engineering Department, University of Technology, Baghdad, Iraq jalalmjalil@gmail.com
\end{abstract}

Received on: 15/11/2018 Accepted on: 10/01/2019 Published online: 25/12/2019

\section{Measurement of Student Outcomes Attainment for ABET Accreditation in Electromechanical Engineering Department in UOT}

Abstract- Student outcomes attainment represents the core of the ABET accreditation. In this paper, a details of the four years' work in Energy and Renewable Energy Program in Electromechanical Engineering Department in University of Technology was demonstrated, concentrating on the process of student outcomes attainment measurement. The attainment of student outcomes represents a challenge in all programs in Iraqi Universities. The process monitored by ABET Foundation expertise through IREX and they approved that the process reached right route although the degree of attainment needs more work in the coming years to reach accreditation level.

Keywords-abet, student outcomes, accreditation.

How to cite this article: Jalal M. Jalil, "Measurement of student outcomes attainment for ABET accreditation in Electromechanical Engineering Department in UOT," Engineering and Technology Journal, Vol. 37, Part C, No. 4, pp. 449-453, 2019.

\section{Introduction}

Abet accreditation became a global target for all engineering programs in the world. Many countries built their national accreditation criteria based on ABET accreditation criteria. The main reason for building national accreditation is the high cost of ABET accreditation. Still, many programs seeking ABET accreditation although they have national accreditation. The achievement of ABET accreditation represents highest global standard of accreditation. accreditation by ABET is indicator that a program has got standards necessary to produce students ready to enter the practical fields of applied science, computing, engineering, and engineering technology. Graduates from a program (ABET-accredited) will have a strong foundation and can lead in innovation, technologies, and in anticipating the welfare and safety of the public [1]. Abet accreditation mainly depends on attainment of student outcomes and all other requirements are helping in creating the environment to achieve this task. The student outcomes represent all scientific and other skills that graduates need to attain to be successful in their future work. The ABET student outcomes are as follow [2]:

a. an ability to apply knowledge of engineering, science, and mathematics (including multivariate calculus and differential equations);

b. an ability to design and conduct experiments, as well as to analyze and interpret data;

c. an ability to design systems, components, or processes to meet desired needs within realistic constraints;

d. an ability to function on multi-disciplinary teams;

e. an ability to identify, formulate, and solve engineering problems;

f. an understanding of professional and ethical responsibility;

g. an ability to communicate effectively in oral and written forms;

h. the broad education necessary to understand the impact of engineering solutions in a global, economic, environmental, and societal context;

i. a recognition of the need for, and an ability to engage in life - long learning;

j. a knowledge of contemporary issues in engineering;

k. an ability to use the techniques, skills, and modern engineering tools necessary for engineering practice.

The attainment of the student outcomes needs to measure and express into number. The tools that used to measure the attainment are called assessments. These assessment could be quiz, report, interview, seminar and question in exam.

In this work, the process of student outcomes attainment will explain in details, starting from 
defining course learning objectives in the syllabus and ending with graphs showing the degree of attainment of the student outcomes.

\section{Course Assessment}

Course assessment was adopted for the course level assessment of the Student Outcomes (SOs). For each course, the outcome-related Course Learning Objectives (CLOs) are defined and also the assessment methods are chosen for each CLO. Each CLO should map onto one or more SOs and then all the SOs could be addressed by several CLOs from various courses collectively. Each course is taught in a manner that addresses all of the CLOs and promotes positive assessment results. The selected assessment methods are utilized to judge whether the CLOs have been met compared to the defined performance targets. Faculty members take responsibility for assuring that the outcome-related CLOs meet the targets and the assessment results are used for continuous improvement of teaching and students' learning. Therefore, the purpose of the course assessment is two - folded as an assessment tool of the SOs for improvement of teaching as well as curriculum.

For the course assessment, the assessment plans including the outcome-related CLOs of the course and assessment methods are set up at the beginning of the year and then the assessment reports including the assessment results and summary are completed at the end of the year. All the year assessment reports should be available for review.

\section{Example of Course Learning Objectives (CLOs):}

EMEE433 - Energy Efficiency and Ethics in Engineering

1. Energy Efficiency in insulation $(a, h)$

2. Energy Efficiency in lighting (a)

3. Professionalism and codes of ethics, Columbia case (f)

4. Understanding ethical problems, Intel Case (f)

5. Line Drawing, Drinking water Case $(g, d)$

6. Firestone Tires and Ford Explorer Car Case $(i, j)$

During 2014-2015 and 2015-2016, the final marks of students were used to measure the achievement of student outcomes. In 2016-2017, this policy was changed after consulting ABET expertise. Specific assessments were performed using performance indicators with rubrics. These assessments were design carefully with standard performance indicators with rubrics and combined with student feedback and are shown in Table 1.

Table 1: Assessed Student Outcomes

\begin{tabular}{|c|c|c|c|c|c|c|c|c|c|c|c|}
\hline $\begin{array}{l}\text { Subject } \\
\text { code }\end{array}$ & $\mathrm{a}$ & $\mathrm{b}$ & $\mathrm{c}$ & $\mathrm{d}$ & $\mathrm{e}$ & $\mathrm{f}$ & $\mathrm{g}$ & $\mathrm{h}$ & $\overline{\mathrm{i}}$ & $\bar{j}$ & $\mathrm{k}$ \\
\hline EMEE111 & & & & & & & $\cdot$ & & & & \\
\hline EMEE122 & & & & & & $\bullet$ & & & & & $\cdot$ \\
\hline EMEE123 & & & & & • & & & & & & \\
\hline EMEE124 & & • & & & & & & & & & \\
\hline EMEE125 & $\bullet$ & & & $\bullet$ & & & & & & & \\
\hline EMEE136 & $\cdot$ & & & & & & & & & & \\
\hline EMEE137 & & & & & & & & & & & $\cdot$ \\
\hline EMEE138 & $\bullet$ & & & & & & & & & & \\
\hline EMEE139 & $\bullet$ & & & & & & & & & & \\
\hline EMEE222 & & & & & & & & & & & - \\
\hline EMEE223 & $\cdot$ & & & & & & & & & & \\
\hline EMEE234 & $\bullet$ & $\bullet$ & & & & & & & & & \\
\hline EMEE235 & & & & & & & & $\cdot$ & & $\bullet$ & \\
\hline EMEE236 & $\cdot$ & $\bullet$ & & & & & & & & & \\
\hline EMEE237 & $\cdot$ & & & & & & & & & & \\
\hline EMEE238 & $\cdot$ & $\bullet$ & & & & & & & & & \\
\hline EMEE239 & $\cdot$ & & & & & & & & & & \\
\hline EMEE321 & $\bullet$ & & & & & & & & & & \\
\hline EMEE322 & $\cdot$ & & & & & & & & & & \\
\hline EMEE324 & $\cdot$ & & & & $\bullet$ & & & & & & \\
\hline EMEE334 & $\bullet$ & $\bullet$ & & & & & & & & & \\
\hline EMEE335 & $\cdot$ & & $\bullet$ & & & & & & & & \\
\hline EMEE336 & $\cdot$ & & $\cdot$ & $\cdot$ & & & & & & & \\
\hline EMEE337 & $\cdot$ & & & & & & & & & & \\
\hline EMEE338 & $\cdot$ & & & & & & & $\bullet$ & & & \\
\hline EMEE339 & - & & & & & $\bullet$ & & & & & \\
\hline
\end{tabular}

The data of these assessments will be used to measure the achievements of student outcomes and it is arranged in portfolio for each student outcomes. The results for 2017-2018 are shown in Figure 1 [3], results for two years are shown in Figure $2[3,4]$, while the results for four years are shown in Figure $3[3,4,5,6]$.

\section{Course Assessments Example (2017-2018)}

EMEE138 - Thermodynamics (3.0, Required)

SO (a) was assessed through assessment of 1 CLO. The class average (71.525) was higher than the target (70\%), No action is required.

EMEE239 - Strength of Materials and Vibration (3.0, Required) 
The class average (63.25) was less than the target $(65 \%)$. Next year, to improve the student's level, more solved problems will give to raise the final grad for this outcome.

\section{EMEE333 - Control System (3.0, required)}

SOs (a, e) were assessed through assessment of 4 CLOs by a different group of test problems. The class average was higher than the target $(65 \%)$ for the CLO1 (73.333\%), CLO2 (75.825\%), CLO3 (70.833\%) and CLO4 (67.91666\%) except CLO4 and CLO3. No action is required.

EMEE433 - Energy Efficiency and Ethics in Engineering (4.0, Required)

SOs (a, h, f, g, d, i, j) were assessed through assessment of 6 CLOs by a different group of test problems. The class average (70.72) was higher than the target (70\%), but individually, $3 f$ (57.13), 4f (56.65) and $5 g$ (57.17) were below the target. This came from the new course to the students (Ethics in Engineering) this year. More time and examples were suggested in describing how to handle the similar problems with various given conditions next year.

\section{Continuous Improvement}

\section{Course Assessments}

The courses assessments results are shown in Figures 1 for all student outcomes.

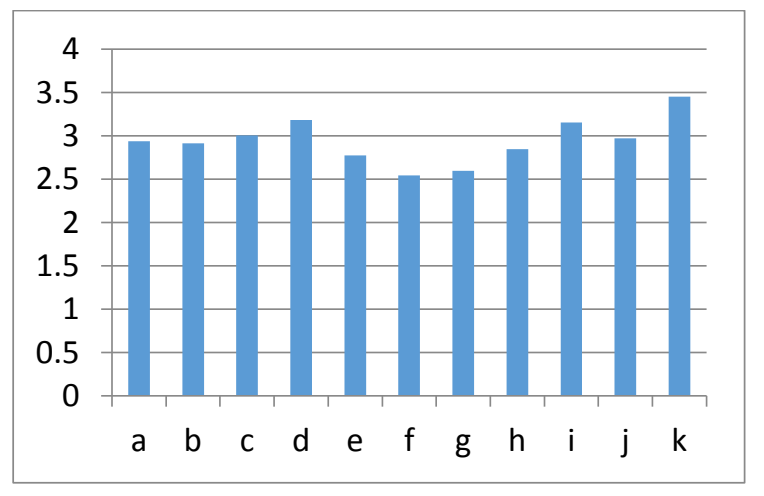

\section{Figure 1: Average course assessment results for outcomes, 2017-2018}

The target of each course was left to faculty to decide. The pass degree to the next level was set by the ministry $(50 \%)$ but there is agreement inside the department that the target should not be less than $60 \%$. The assessment results for all courses were passed (2.5/4) (62.5\%). Which seem acceptable this year except for ethics course.

In Figure 2, the results of 2017-2018 was compared with last year results 2016-2017, there is a clear improvement in most of the outcomes except g, e, and $\mathrm{f}$.

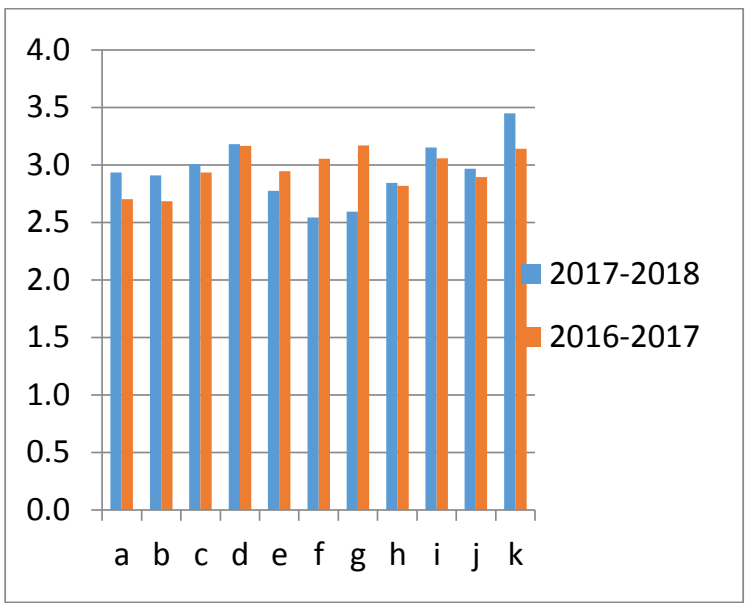

Figure 2: Average course assessment results for outcomes, 2017-2018 and 2016-2017

In Figure 3, the results of four year were shown; the improvement was clearly shown through the years. The improvement comes after many workshops through the years. The workshops were concentrate on how to build an assessment based on professional rubrics so the results will really show the attainment of student outcomes. The assessment could be quiz, question in exam, report, interview while in years 2014-2015 and 2015-2016, the assessments based only on student marks in exams and not based on rubrics.

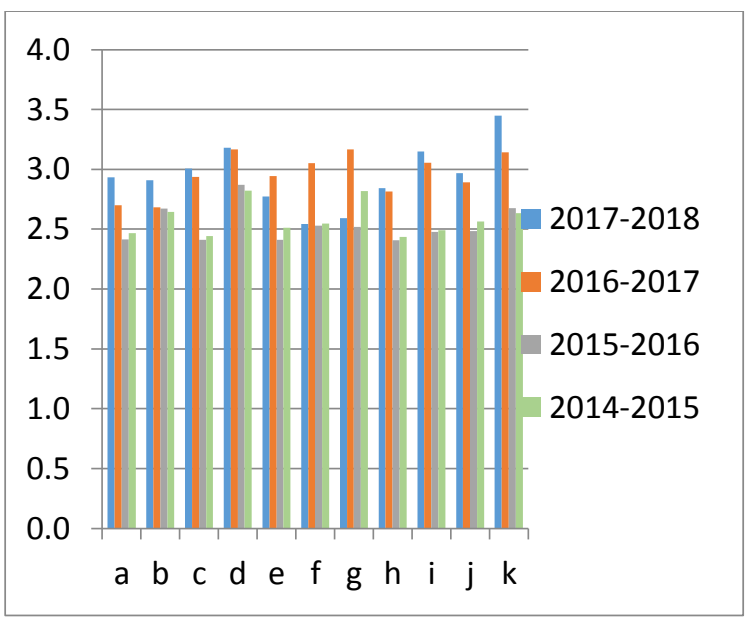

Figure 3: Average course assessment results for outcomes, 2017-2018, 2016-2017, 2015-2016 and 2014-2015

II. Continues improvement planned changes: Past Improvements: 
- Establish Industry Advisory Board in 2015-2016, with yearly meeting. Through the meeting, the employers feed the curriculum with field problems and required skills for the graduates.

- Build portfolio for each course and for each student outcomes (2016-2017) to make assessments data collection systematically.

- Courses evaluation changed from exam final marks to carefully designed assessments with professional rubrics (2016-2017) to improve student outcomes achievements. The rubrics give details of the student outcomes requirements and also improve the teaching techniques of the faculty.

- Introduce student ratings in the course portfolio to supply feedback to the faculty and also to department administrative. The student feedbacks were a great benefit to department council to improve faculty performance (2016-2017).

- Introduce problem based learning in the department, nearly $20 \%$ of the staff are using this method now. The method makes attainment of student outcomes easier (2016-2017).

Present Improvements (2017-2018):

- Correct credit hours of three main categories (math and basic science, engineering and general education courses) according to abet limitations.

- Collect student works for each assessment.

- Increase general education credit hours from 6 to 8 hours by introduce ethics course.

- Establish many symposiums with ministries concentrating on necessary graduate skills like team work, ethics, and communication.

- Establish many workshops educating the faculty about necessary student skills like team work, ethics, and communication. The workshops were performed under supervision of IREX (American International Research \& Exchanges Board). IREX helps to carry American Universities experience to Iraqi universities.

\section{Future Improvements:}

- Build a comprehensive plan to change courses from whole year to semester, it will apply in 20182019. The plan comprises:

- Reduce the number of courses from 35 whole year courses to 42 semester courses. The plan allows only 6 to 7 courses in one semester.

- Reduce number of credit hours from 142 to 130.

- Introduce 2 elective courses in 2018-2019.

- Change to Modules system in 2019-2020, which needs ministry's approval.

\section{Results and Discussion}

This work is a primary effort from Energy and Renewable Energy Program in Electromechanical Engineering Department to get the ABET accreditation. Through four years of work (20152018), the work was reached good stage in approaching the accreditation level. In July 2017, the Self Study Report of 2016-2017 was evaluated virtually by ABET Foundation expertise. The virtual evaluation was financed by IREX. The result of evaluation was encouraging as follows:

\section{6-2017 Virtual Evaluation by ABET Foundation:}

"The program would likely be accredited, but with several issues that would need to be fixed (cited in the report). Two critical areas that appear lacking are:

- No actions to improve the program (Criterion 4)

- Only two courses in general education (Criterion 5) “

So the effort was continued in the coming year (2017-2018). In July 2018, the Self Study Report was evaluated again friendly by ABET expertise, again the result was encouraging as follows:

2017-2018 Friendly ABET Expertise Evaluation: "Attached are my comments. I went through criterion 5. This is well written and provides the information that an ABET PEV would require. I have included many comments, but they are focused on what you would need to include if you are actually seeking accreditation. This Self Study is as good as many I have seen here in the US. Your processes are generally in compliance with the criteria and I think some minor modifications to them and slightly more direct communication in some instances would bring you to the top. You are clearly doing the right thing in assessment, although I would make some labeling changes for clarity and reduce the amount of assessment that you are doing for some outcomes.

Overall, though, the Self Study portrays a_program that, in my opinion, could be accredited by ABET. Nice job!"

This success was encourage the Electromechanical Engineering Department to ask finance from Ministry of Higher Education to submit formally a request to ABET accreditation 2018. 


\section{Acknowledgment}

This work is a mutual work for all faculty of Energy and Renewable Energies Branch in Electromechanical Engineering Department in University of Technology (Baghdad Iraq). The support of the Dean of Electromechnical Engineering Department is gratefully acknowledged. Thanks to all faculty of Energy and Renewable Energies Branch for their corporation in performing this work. Also special thinks to IREX for their supporting during the four years of work.

\section{References}

[1] https://www.quora.com/What-is-the-importance-ofABET-accreditation
[2] http://www.abet.org/accreditation/accreditationcriteria/criteria-for-accrediting-engineering-programs2018-2019/\#GC3

[3] Self-Study Report, Energy and Renewable Energy Program, Electromechanical Eng. Dept., University of Technology, Baghdad, Iraq, 2017-2018.

[4] Self-Study Report, Energy and Renewable Energy Program, Electromechanical Eng. Dept., University of Technology, Baghdad, Iraq, 2016-2017.

[5] Self-Study Report, Energy and Renewable Energy Program, Electromechanical Eng. Dept., University of Technology, Baghdad, Iraq, 2015-2016.

[6] Self-Study Report, Energy and Renewable Energy Program, Electromechanical Eng. Dept., University of Technology, Baghdad, Iraq, 2014-2015. 